\title{
The Fit between Business Strategies Ethics and the Approach to Total Quality Management
} A Suggested Model

\author{
Dr. Ali Hadi Jebrin \\ Associate Professor, Department of Business Adamantration \\ Arabia Amman University - Jordan \\ Tel: 96-279-909-9991 E-mail: Daad_Ali@yahoo.com \\ Dr. Mohammed Ajlouni \\ E-mail: Moiaqbal2002@yahoo.com \\ Received: September 9, 2011 Accepted: September 20, 2011 Published: January 1, 2012
}

doi:10.5296/jmr.v4i1.938ＵRL: http://dx.doi.org/10.5296/jmr.v4i1.938

\begin{abstract}
The research comes to solve the extent of influence that can be caused by the fit strategies to business ethics for quality management over the approach to the competitiveness.

The objectives of the study are as follows:

- Identify the trends and qualitative dimensions of the principles of business ethics and the possibility of support and to be assigned in the application process.

- Diagnosis of ethical principles and qualitative dimensions that influence improving the competitiveness of the fit direction.

Despite this the study being a theoretical study, trying to reach a preliminary step to a scientific concept of dimensions of quality and ethical principles as its foundation, and finally propose a model to study “The Fit” between Axis the qualitative and moral.

Importance conclusions more: There is a need to link the central business ethics and the approach to Quality management, or to say that there is a missing link between the two Axis, can be achieved through the Integral framework towards achieving the "The Fit" between the two Axis, which is an important pillar in the work, objectives and plans required to improve the performance and competitiveness. While the Recommendation that: the study proposes the, "the fundamental principles of business ethics of the "Total Quality Management" based
\end{abstract}




\section{Macrothink

on proposals theoretical frameworks to the approaches of selective business ethics and the human rights entry and the theory of distributive justice and the single entry and then the virtue entry and ethics.

Keywords: Business Ethics Strategic, Total Quality Management, Competitive Capability 


\section{Introduction}

Products of high-quality are considered the foundation and goal that Being described as a strategic goal can be reflected on the results of the Strategy for companies, in particular those dealing with environments which are dominated by competition. The ethical responsibilities are considered a quality management task that depends upon the company by strengthening its ability to compete.

Miller stresses on a case for many of those interested in, when he showed that the causes of decline in the share market for many companies, is due to Focus on traditional management concepts "profits, bonuses, cost" in addition to looking at the results in the short-periods(Miller, 2007)

From the foregoing we can understand that the strategic location of the Target quality is what led to the adoption of contemporary management skills to tell us things as nobility, confidence, a tendency towards ethical orientation of the decisions and actions, however, it requires that managers Focus all their attention to the values and ethical considerations in the implementation of Objective qualitative strategic, and this reinforced the Emergence of the concept of total quality management, and shows such an interest in theory in conjunction with the Department entrance moral (Chen and Williams,1997)

That has raised the interest in the field also in the evaluation of the reasons for the success of many international companies.

The success of Total quality Management objectives (TQM) lies in the formulation of a clear understanding of relevant environment aspects, and determines the suitability of ethics and moral principles regarding the dimensions quality requirements of the application of the "total quality management."

Based on the above, which highlights the importance of this study, and develop a methodology for the consideration given to what is expected from its modest contribution to the unfolding theory to the subject of strategies, ethical and Total Quality Management in addition to its contribution in the transfer of those features represented by the nature of "appropriate" between the dimensions and principles of the Axis, and here is This study bold modest contribution in the field of fertility, is in dire need for further research.

Consistent, the current study, and despite being a theoretical study, trying to reach a preliminary step to a scientific concept of dimensions of quality and ethical principles as its foundation, and finally propose a model to study the appropriate Axis between the qualitative and moral.

Trying to study the research adoption framework inductive and deductive we adapt a methodological framework which is as follows:

1. Define the problem of the study and its importance and its objectives.

2. The interrelationship between quality and business ethics.

3. Strategic directions for total quality management. 
4. Strategic directions for business ethics.

5. The Fit between business ethic strategies and total quality management approach.

6. Model Suggested

7. Conclusions and Recommendations.

\section{Define The Problem And Importance of Study and Objectives:}

1.1. Define the problem of the baseline study, it is necessary to look at the relationship between quality and ethics in the light of theoretical models that link the relationship and the method of promotion, as an integrated vision of the problem is subject to the nature of the model adopted in the study, which could take pictures the following:

1.1.1. The following sample shows that the culture that produces quality culture of the organization which provides the content or the window that is created when the organizational climate(Kant,1997) as shown in the figure(1).

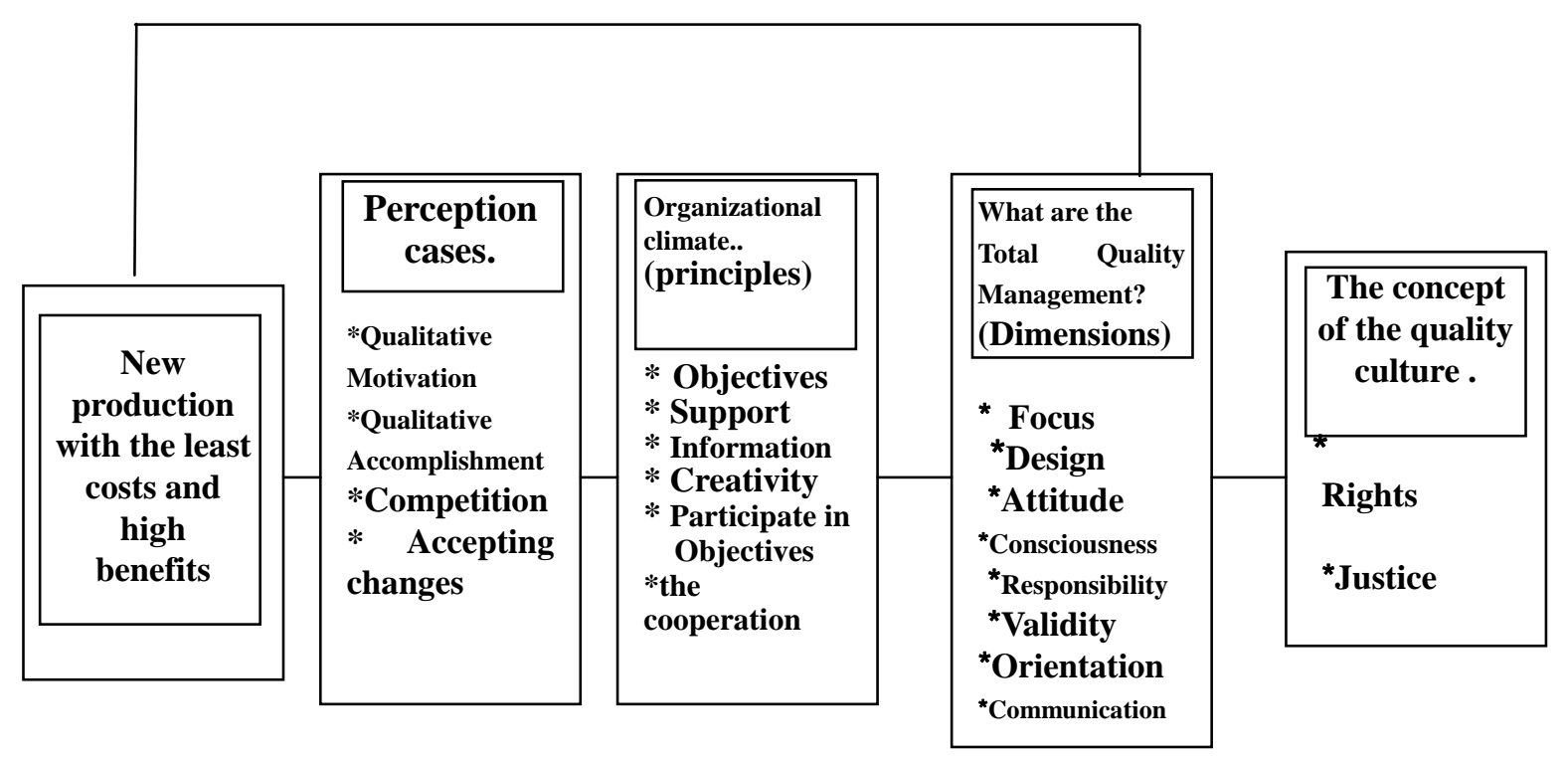

Figure1. Cultural quality and culture of the organization and its relations

The approach to "Total Quality Management" can not succeed without preparing many of the most important requirements; especially the organizational climate which is dominated by a positive culture cooperation and partnership, innovation and support.

The problem is that model dimensions and the principles adopted in the process of interdependence, as they do not give a clear vision for how to follow up the impact of each one of the trends mentioned "qualitative and strategies ethical," as it does not assess the weight of the appropriate issue among themselves and the impact on the final results.

And notes that the studies focus on the dimensions of the approach to the Total quality management can not only pay off if appropriate to the ethical principles of the strategy. 
1.1.2. In order to achieve the objectives of in the growth and expansion and construction of the organizations they realized that there is a relationship between quality and ethics(Chen and William,1997,pp.855-865) and this relationship support the world of quality (Deming) in a series of relationships which is shown:

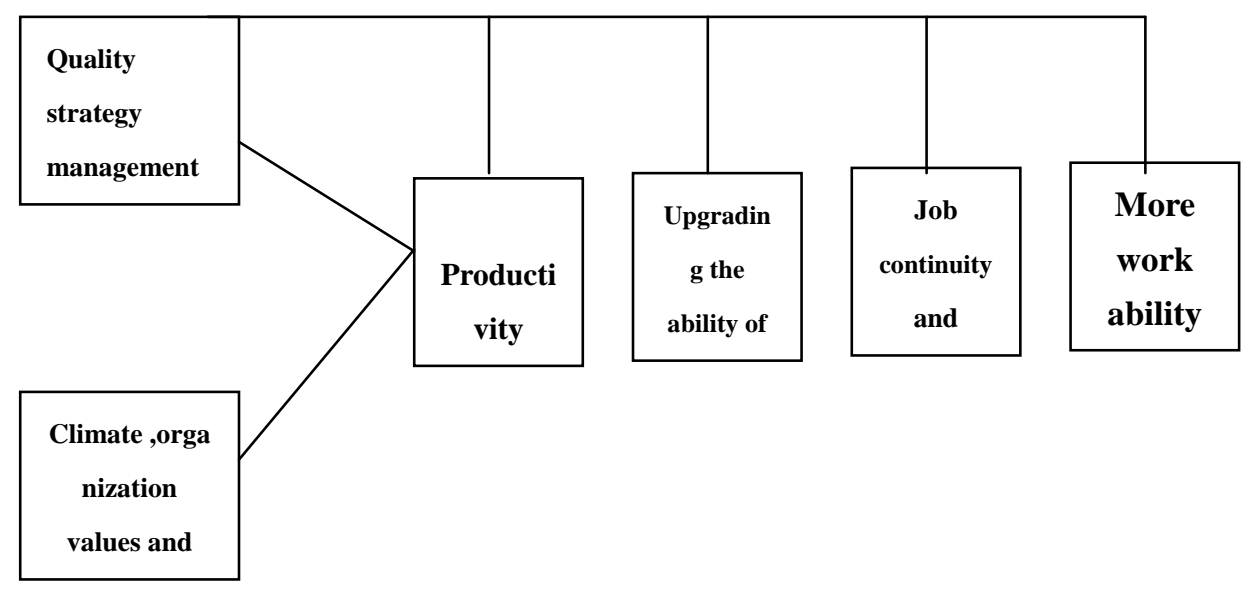

Figure 2. shows the relationship and interdependence Between quality and organizational ethics

This figure shows where the process of interdependence in the light of the organization expectations in the similarity between value and goals with the values of quality and strategic objectives, and here lies the problem in the light of the data, the model is based on the assumption that the climate and organizational values greatly influence by the environment of the Organization through the entrance to quality management strategy, but do not indicate any signs of the presence of fit direct Axis and determine the dimensions and principles of the moral influence, but stems from the factor values and change perceptions that it is important trends in the internal environment of total quality management, which improves the productivity of the company to serve the trend towards better performance and competitiveness in order to achieve the objectives of the company's growth and expansion and survival.

1.1.3. Including that the state the fit cases commonly found in the link between the central administration the total quality management and strategies ethics, and therefore a model of the impact of mutual is an urgent need, therefore, the current study primarily aims to Find integrated model tries as much as possible to achieve the status of Alignment of the tow Axis , the essential study problem lies in following the dimensions of total quality management in the moral strategies, but how to achieve adequate fit between the parties to the appropriate equation, the question remains, which has no decisive and clear answer in the theoretical and empirical field, depending on the current information this study attempts to solve this problem:

* How does the strategic decision-makers to business ethics at the entrance of total quality management?

* Is there a strategic vision to develop the qualitative dimensions of Total quality 
management?

* Does the senior management in contemporary organizations have clear perceptions about the basic principles of ethical strategies and priorities to establish and rank?

* Is the appropriate between dimensions and total quality management strategic principles of ethical correlation and mutual influence towards the achievement of good performance and improve competitiveness?

1.2. Importance of the study and its objectives: the business ethics subject in the developed countries acquire a strategic importance which reflected clearly not in what studies and research of their jurisdiction, but it extended to the reality of the work of those companies in practice.

The researcher believes that developing countries, still face problems of their origin which is linked to the existence of a distinct lack of quality and its dimensions and its role for companies in those countries to be an incentive to rush towards the disclosure of benchmarks that can be is used by industrial companies and service organizations in order to find its place in the midst of competition.

Based on the above we address the extent of influence that can be caused by appropriate strategies to business ethics for quality management over the entrance to the competitiveness.

Based on the above we can determine the objectives of the study as follows:(a) Identify the trends and qualitative dimensions of the business ethics principles and the possibility to support and assign the application process. (b)An attempt to explore the scientific bases for the concerns of the ethics theoretical subject, business and strategies, as well as qualitative dimensions of the entrance to the Total quality management, so as to devise and develop ideas we have tried to find points similarities or difference with the view of the researchers and specialists through what we have established of a clear methodology and what we have done of the theoretical analysis, the contents of this effort aimed at establishing a new understanding of the meaning regarding the principles of fit business ethics to the approach of Total quality management and scientific content of the variables and their own to achieve good performance and competitiveness.(c)The Diagnosis of ethical principles and qualitative dimensions which influence in improving the competitiveness towards the fit .

\section{The Interrelationship Between The Quality And Business Ethics :}

Many studies and research that surveyed the area and qualitative analysis of the concept, the quality in today's hyper-competitive and diversity of products or services provided and the tastes of the growing consumer demand.

This research consider the criteria of quality from a economic point of view based on the nature of the relationship between macroeconomic and administrative theories, we find the subject of quality in the ideas of

(Stewart 1967 -1981) (Taylor1915-1850,) (Gibert1924-1868) a milestones of interest spread across the stages with the development in the fields of industry and its different periods, is 
deemed the efforts of the statistical (Pearson) to apply the law of statistical in (1939) in consolidation Metrology Industrial control quality, which has become recently a part of the industry and one of the milestones in the development of attention to quality, and in the light of these important emerged trends in different quality depends on the point of view the method used, first, highlight its importance within the vision of moving toward task managers processes variables and many dimensions in the production process affect the quality of the product, and this theory is presented on the assumption that through increased productivity, and this is what was determined previously that the experience of a higher productivity and economic development is the use of quality.

The other approach, represent the view of the customer about what is desired and what he needs and requirements to achieve the very foundations of the relevant ethical principles and strategies under the concept of social responsibility(Kant,1997,pp.83-86)

In order to understand the previous perceptions, we found it appropriate to shed light on the content of the concept of interdependence between quality, ethics and strategies in the context of recent trends through a process of comparison between the concepts of quality according to the entrances of the economic trends of contemporary and earlier in the light of the link to quality with moral strategies, and concentrated comparisons in the light of the model put forward by (Tobin) in focus, accountability, measurement, terms of reference, orientation, and the table (1) reflects trends comparisons(Tobin,1990).

Table(1) Comparisons between the actives of quality under the concept economic theory and ethics

\begin{tabular}{|c|c|c|}
\hline Activity & $\begin{array}{l}\text { Direction Within the Concept of Total } \\
\text { Economic Theory }\end{array}$ & $\begin{array}{l}\text { Direction Within the Concept of Ethical } \\
\text { Approaches }\end{array}$ \\
\hline Focus & $\begin{array}{l}\text { * On the demands of } \\
\text { Management } \\
* \text { On manufacturing } \\
\text { * Quality of narrow interest }\end{array}$ & $\begin{array}{l}\text { * The Wishes of Consumers } \\
\text { * All Departments } \\
\text { * Quality Becomes a Way of life }\end{array}$ \\
\hline Responsibility & $\begin{array}{l}\text { * To achieve Profits } \\
\text { * Reduce Errors } \\
\text { * Hide Quality Indicators } \\
\text { * Do not Accept The Change }\end{array}$ & $\begin{array}{l}\text { * The Profit and other Goals } \\
\text { * Zero Defect } \\
\text { * To Disuses the Quality of the } \\
\text { More Obvious } \\
\text { * Accept the Change }\end{array}$ \\
\hline Specialty & ${ }^{*}$ Group is Responsible & $\begin{array}{l}* \text { The Establishment of Task } \\
\text { Forces }\end{array}$ \\
\hline Measurement & $\begin{array}{l}\text { * Quality as a Single Property } \\
\text { * Inspection identifies } \\
\text { Unacceptable }\end{array}$ & $\begin{array}{l}\text { * An Important Quality, Multi- } \\
\text { Properties } \\
\text { * Must have every Person } \\
\text { Trained by Method and } \\
\text { Quality Standards } \\
\end{array}$ \\
\hline Orientation & $\begin{array}{l}\text { * The Department Strives to } \\
\text { Achieve Short- Time Result } \\
\text { * The Quality is Function }\end{array}$ & $\begin{array}{l}\text { * Long- Term Results and Striving } \\
\text { To Improve Processes } \\
\text { * The need for Quality Competitiv }\end{array}$ \\
\hline
\end{tabular}


On the other hand it was proved by the studies of experts for quality (Deming, Juran) that more than (80\%) of the causes of deviation in quality affecting the productivity of the responsibility of senior management and, if so, without desire, and senior management leadership can not be acquired for this activity(Jurn,1988).

It is useful here to cite what he says (IshiJawa) about the senior management study quality, and refers to the relationship between quality and ethics based on the concept (Kaszen) which confirms the continuous improvement of business and focus on improving the quality of people, and that the objectives of quality is the goal of every manager to being an important competitive (Ishikawa,1985). and questions to (Smith) the President of General Motors Corp. about the importance of quality and its strategic role he speaks they no longer process control or inspection, but it is a strategy a moral in the company and take precedence over other strategic objectives, and therefore the quality is one of the social responsibilities the most important for senior management as they relate to the culture of the organization and its ability to compete (Milakovich,1991).

So it's a methodology to achieve coherence and substance of the relationship between quality and ethics in the light of contemporary concerns centered two-way, confirmed by the studies (Hedgeits,1994; Weihrich,1994) First, deals with what lies beneath the concept of "total quality management" entrances and dimensions, which could be clarified as follows:

1.2.1. The signal of (Vijay) emphasizing a focus on qualitative dimensions of the base on which to proceed in building an efficient quality management to improve performance and competitiveness (Vijay,1985).

1.2.2. The objective of the study requirements and the needs of the market, according to the opinion (Harrison) is, in essence, identifying the entrance to a contemporary of total quality management can be the product or service to improve the competitive ability of the company(Harrison and Janice,2003).

1.2.3. Understanding the process of production and attract the attention to all the processes as (Terrence and Allen) concluded is the need for reality and a vital part of the basics of total quality management(Terrence and Allen,2001).

1.2.4. Those who study the books on contemporary trends on total quality management will notice the insistence of the writers toward the moral interest in identifying the appropriate strategies (Steeples,1994).

The second axis that fall under the concept of moral strategies, and philosophy can be annotated in their application as the following:

1.2.1. It has become a business in accordance with (Thomas) in ignore of the impact of the principles and elements of ethics, quality, and build understanding of the requirements for an efficient Total Quality Management to accommodate the needs and desires of the according to the consumer(Thomas,1993).

1.2.2. The other prove is choosing appropriate systems and appropriate in the total quality management towards the achievement of social integration and promoting coherence through 
the use of business ethics, which leads to the stability of staff and activities to achieve efficient quality of work(Steeples,1994,p.74).

1.2.3. (Murphy) continues in his study to the conclusion, that the modernization of information systems improve the chances of collecting the information needed to achieve an approach in which knowledge changes prevailing in the wishes and needs of consumers in order to change the general position of the company towards the achievement of this desire, as the consumer is really the basic ethical in quality management in their plans and programs (Murphy,1999).

1.2.4. The study, carried out by (Lee) to the conclusion that the managers focus to address relevant problems or link to climate or trust regulatory and normalization and organizational gaining importance, given that these problems stands usually an obstacle to the possibility of improving the company's ability to compete, and the focus of this attention focused on the requirements of improve the participation of workers, form a team work, commitment, acceptance, problem solving, innovation(Lee,1993).

\section{Strategic Directions For Total Quality Management}

(Crosby) defines "Total Quality Management" as a structured way to ensure that the activities of industrial companies or service, intended to prevent problems by creating a structured behavior management(Crosby,1989). With the increasing importance of quality strategy, increased attention by managers of international organizations towards changing the way their departments, if they wanted to build a ground competitive, as it became clear that most managers in the world look to the ethics of a way to address the problems of quality and the trend towards business ethics as a matter of strategy, and this will require radical changes in the way managers approach to quality (ASQC,1986).

To confirm this the of the American Society for Quality Control (ASQC), indicate that more than $80 \%$ of the administrative leadership has realized that there is a relationship between quality and ethics, the same studies indicated that this ratio between quality and productivity. And support this relationship world quality (Ishikawa), and this is what was discussed earlier in which able the individual to learn the systems of quality control for this, the main goal of this relationship in an attempt to deliver the picture of the individual to the organization's culture and image of the Organization of the culture of the individual(Ishikawa,1985,p.29).

It is clear from the above, that the objectives of the operations in lower cost and delivery of good and fast and use of systems and techniques of production may be achieved from the impact and the role of "total quality management" as the process by which the individual acquires models and behavior of Technology or a possession of synthesis indicate, and administrative organizational units both become able for the disposal of some of the trends that keep him that it would be a bad influence he brought from the external environment that are not consistent with the orientations of the organization.

And thus managers become in need for new ways of thinking to serve the consumer, they should choose or devise or after a set of dimensions by which discuss the quality as moral strategy(Steeples,1994,pp.73-75). 
This is consistent with the interest of business organizations to achieve the following objectives(Mayo,1991).(a) Promote and achieve the satisfaction of consumer desires and needs.(b) Acquire and enhance competitiveness.(c) To achieve strategic goals of the company on long ranges.

And continue with these ideas were (Water) suggested that quality, begins with the knowledge of what it needs the consumer through marketing research and development towards the study of ethic works and focus on the principles and determine the dimensions that can be relied upon to design and build a moral satisfaction of people(Water,1991).

We have found in focusing on the requirements of consumer a base which we can build on them in determining the dimensions of adequate quality to be a measure of the entrance to total quality management and a path towards competitiveness, is such a perception in line to the wide limits with the view of the majority of Japanese manufacturers since (1950) and beyond (Deming,1982).

At the same time the researcher found that the American Society for quality control (ASQC) in the context of its view of the quality did not diverge from imagining the former from the fact that quality is not only the shape and qualities of the overall product appropriate to the specific needs and it emphasis on the needs of consumers are not only the driving force for the strategic choice of quality representative dimensions of competitiveness, and that the company pursued a strategy that it should develop a competitive dimensions of quality, through a conscious awareness of business ethics and values to meet the requirements of consumers and their expectations(ASQC,1986,P.8).

Based on the above, the researcher did not find exhaustive model agreed by the researchers to identify a variety dimensional portal "Total Quality Management " for the fit strategies ethics, but we are in the construction of our model study, we tried to focus on points of agreement targets that achieve the greatest possible degree of inclusiveness, sponsors that such property is theoretically available to acquire practical importance, as follows:

\subsection{Context quality:}

Content as expressed in (Linkow) by the prevailing climate in the company which represents the philosophy and organizational culture(Linkow,1989) in a study of (Don) the prevailing environment in the company, stressed that it had the basic rules by showing people how to behave in more times, and the position or direction of moral General of the act(Don,1988).

In this regard, stressed the same author that managers should be aware that whatever made them the technical and sophisticated equipment, they are not enough, if not reflect the values and beliefs prevailing in the company by the workers and people of the importance prefer the good quality presented to the consumer, especially when the workers are the real key to quality, and the degree of development and improvement of quality and achieve the results will be gained when special senior management trust the efficiency of each worker in his creations and his contributions in quality work.

In light of this, the company should pay attention to that quality which is the element of 
power based on their strategies as (Glenn) called it of embracing personnel attitudes and values, and innovation, in order to identify all that is possible to be achieved higher levels of quality, and stressed that it requires the generation ahigher levels of cooperation and cohesion because this situation will happen as an organizational commitment as well as the desire to follow the instructions and procedures restricted down(Glenn,1985).

\subsection{Empowering Employees:}

Empowerment is giving employees the authority to implement the work required by his position within the organizational structure, so the success of "Total Quality Management” on the ability to influence Organizational behavior and to achieve the positive balance in the words of (Tom and Austin), and in order to become the administrative practices of moral successful in supporting quality strategies to improve competitiveness, (Rosabeth) confirms that the contribution of the individual worker's activities in support of quality, through acquired skill and experience through training, and providing the information and moral support to help him achieve contributions lead to the development of quality activities(Rosa,1989).

The importance of research reflected on the "Empowering Employees" with interest by several authors in the attempt to meet the needs assessment and proof of individuals by making their work more challenging tasks and give them greater responsibility.

The researcher role here is to emphasize the importance of empowering employees as one-dimensional quality to the fact that this dimension means the contents of individual interaction in the group with mental, emotional and social well with the senior management team, the administration should give special interest because he represents one of important topics in the process of competition.

\subsection{Communication quality:}

Perhaps (Ishikawa) is the one who clarified the concept of staff communications on a broad basis, he outlined that they constitute two frames, the first collaboration (the staff affect decisions but they do not they make it at the end), and this includes their rights to receive information and provide advice and proposals and the right to openness and to object to decisions, but The second type, it is the dialogue (conversation), and here are their rights of veto and rejection of the provisional and participation in decision-making(Ishikawa,1985,p.29).

Communication activity between staff enhances the coherence of the group and team spirit when it is content-oriented goals and plans.

To achieve this, the researcher sees the need to identify successful communication processes in the areas of ethics quality work according to the following:(a) Giving the opportunity to interact through the establishment of teams and through a collective feeling that is born of its members in a spirit of cooperation, to enable them to learn their vocabulary.(b) Guide the interaction between individuals to open dialogue and discussion of each factor with other staff and each department with other departments to analyze the implications of their actions 
in the light of their experience to identify problems and find solutions to them.

And communication is not curing medicine to each disease, but its use is expanding rapidly to achieve the advantages and purposes, among the advantages in the application as follows (Don,1988,p.38):(a) help the process of effective communication in quality to achieve the essence of the human individual in the consuming of the company and improve the efficiency of the planning process.(b) Communication creates the process of compatibility between knowledge and knowledge of senior management departments, other departments in the nature of its activities towards creating harmony and common understanding about quality.(c) Communications can appropriate information to link the efforts with rewards and application of incentive systems and this is what creates new aspirations and stimulates the development phase of quality.

\subsection{Eliminating Barriers:}

One of the issues and the basic facts in the qualitative behavior, that there are problems and limitations and obstacles during application and some of them are the following:

3.4.1. (Rosabeth) Pointed out that the question of the low level of quality, due perhaps to focus on control and correction after the occurrence of the disorder, and this generates a weak commitment by management about the activities of quality, what is required from the administration to emphasize the prevention of an imbalance and act in accordance with the principle of "Make it right from the first time"(Rosabet,1989,p.34).

3.4.2. The perception of quality is the responsibility of a specific department, pursuant to the erroneous and disabled, and is true that quality is the responsibility of all of his relations to operations, includes multiple responsibilities in manufacturing, engineering, marketing, procurement and therefore For sections are all contributing to the achievement of tasks(Schroeder,1989).

3.4.3. The belief that quality is limited to inspection is unacceptable, Quality is a strategic aim of which company to improve competitiveness, and this requires an understanding of senior management quality assignments, and its one of their responsibilities.

Thus, what was viewed previously is to account for important dimensions of the necessary "Total Quality Management " philosophy and content are a reflection of the reality of actual business ethics and attempt to discover the impact on the performance and improve competitiveness may not reach the limit inhibitor of the Whole, as could arise from factors other dimensions, either by dynamics of environmental variables and their interactions or the impact of various technological developments and the fever of competition.

What have been briefed of interpretations of researchers and was concluded in purported or extrapolation remains our view, which offers purely theoretical gain credibility in the treatment field.

\section{Strategic Directions For Business Ethics}

Meaning of moral in language is Religion, Attitude, Generosity and nature and which implies 
the power of entrenched will tend to what is good or evil.

The historians specifically Aristotle, who came up with the first ethical theory, is built on the basis of "virtue", and the moral virtue that is subject to the mind and can be acquired with training and practice. And justice in the thought of Socrates is to regulate the standards superior virtue, while justice in Plato means "equality" and end against the ethics, the concept of justice is governed by three sets of values are the individual organizational and social values and form of these groups, the so-called rules and ethical behavior.

Our assessment of the ethics depends on not on the purpose of this narrative history of the entrance, but the reference to the link with total quality management principles or ethical behavior which expressive and stimulate on improving quality.

During our analysis we have not found a scientific research to help us to conclude that awareness of work ethics is reflected on the reality of the organization and planning its relationship concerned with total quality management. In today's society we appreciate that the issues and cases of deterioration in most companies due to the nature of the relationship between the manufacturers or service providers and their customers and this leads us to a crisis imposes itself related to ethics, quality work, while we find that corporate managers tend to link these issues and cases to the expectations of customers who grape their attention to it had to be characterized by the decisions of managers strategy and plans, the expectations of the ethics of quality and how it relates to the practical reality in senior management and the relevance of this concept to the values of the individual and organizational values and social is easy to understand management of the administrative process and contribute to the achievement of its objectives, which also facilitates the creation of organizational climate Collaborating product, which provides for the creation of an atmosphere of relations environment organization with the spirit of understanding and cooperation.

In addition to that view, and to be able to distinguish between ethical and unethical to be presenting the most important entrances ethical still important and relevant to our study as follows(Machold and Ahmed,2004).

\subsection{Selective Entrance Utilitarian (Utilitarian)}

The focus of this approach on the ends or goals, is an approach that concerned with the final outcomes, that the work of managers under this approach leads them to search for possible effects of the acts and actions to achieve the benefit and deliver it to employees, and in this field, (Barnard) says, "What he means" that the goal of the organization must be morally and this must be the moral purpose embedded in the fabric of the organization he means, the purpose of doing actions should not be of an ethical purpose but the objectives should focus on the quality of the product or service, not profit(Grant,1997).

In the view of (Sawyers and Williams) that senior management determine the factors and ethical standards that guide managers in all levels(Roth,1993,p.38). if the purpose or goal to improve the quality of the product or provide the best service in terms of moral, the initiative must be from senior management to focus on the moral values within the organization. And develop a sense of the public understanding of ethical issues in accordance with the concept 
of Aristotle.

\subsection{Entrance of Rights: Ethics (Kantion)}

This approach focus on the basis of philosophy (Kant) and the term universal rights derived from the Greek word we mean the duties and obligations, any legal validity according to the logic of implementing ethical rules. It is our duty not to harm others because of "the right thing by working" and to not violating the rights of others(Kant,1997,pp.83-86).

This helps us to issue provisions on the harmonization of behaviors and decisions made by others with the principle of equitable distribution of the other according to the concept of (Socrates), and download the burdens and costs by all individuals and groups, and this entrance make varieties imperative mission to illustrate the concept of moral rights of the behavior of the ethical within the concept of total quality, which focus the following:(a) The strain and pressures resulting from the efforts of others caused by the normal processing of objects by people.(b) The act or the work which is a result of the humane treatment, you do not own the others.(c)Pressures as a result of consumer demands and the needs of customers according to their wishes because of individual freedom, rational possibilities, and the correct moral choice.

(Kant's) theory starts within the entrance of the philosophy of "good will" "Careful" and the concept of guaranteed good quality, the idea is applicable, with good practices such as the right of life, in select the product or service required, protection and safety risks of the product, credibility in the quality of reliability and performance, private property, respect the views of the public demands, to provide your own beliefs and desires according to delivery (Kant,1997,p.85).

\subsection{Theory of Distributive Justice: the Ethics of (Rawlsian)}

Seems that the theories mentioned do not confirm the principle of justice in the work ethic under the changing circumstances faced by organizations of work, which led to the development of a perspective more effective based on two contemporary theories of justice within the concept of ethics (Rawls's), constitute the first theory the idea of integration between ethics and technology progress by (John Rawls) in 1971, and second, the justice that takes precedence in the founding of the Society, participation comes to ethical factors which derived from the concept of equity and justice appropriate, Integrity, Agreement, equality in distribution, both of these to achieve the benefits of human and distribution of fair share (Rawls,1971). and managers running these principles in the exercise of the powers and the performance of duties and bearing the responsibility of everyone and their sense of that quality work is the responsibility of everyone to achieve strategic objectives.

We believe that the training program will contribute to establish the value of justice on the basis of reason and logic in the business organizations of the strategic qualitative dimension and the consequent concentration of justice in the fabric of the organization and its life to overcome the problems most productive or service sectors.

\subsection{Single Entrance: Ethics (Robert Nozick)}


A model for the evolution of moral and ethical at the individual level, the primary value of this approach is the choice / freedom Layer (Nozick) (1974), which is one of the most important requirements for building community, and society in his view is to take or thread individually and collaborator of the founding and growth of the national economy(Roth,1993hired by the Union former USSR, has deployed a team of U.S. interested in the qualitative study on the qualitative development and productivity, and concluded that the substance caused by the movement of reconstruction to improve the quality of products and services. This gives any person the ability to judge what is right or wrong and discrimination, the fact that the principle of cooperation to achieve wealth, income products, services.

\subsection{The Entrance Of Virtue In Ethics: (Virtue)}

It is appropriate to shed light on this subject, in addition to our prior reference to that virtue in the moral theory of ancient origin and philosophy of Greek, discussed this entrance by a large number of authors interested in quality one of them (Alasdair Macintyre, 1981), which added to the concept of related properties, The first one is "reflect the excellent"(Chen,1997,pp.855-865).or "do it the first time" as a philosophy (Crosby) and the idea of morale, courage, self-moderation, in addition to the concept of justice.

In (1994) there was broad acceptance of this concept or the definition and the support that (Childress), which springs from that Virtue is the basic swab or property of the task, one of the virtues of social values and business in general practice is good and the harm and the requests are all concepts we have learned "how to think(Childress,1994), and that individual requests that organizations strive for it, is one of the most important basic principles to achieve balance in the quality of thought and the legal relations between groups in society.

In our awareness to continue what catches the interest of specialists in this field, the above approaches of morals represent the beginning of the cursor in the development of a perception of those entries and principles regarding the Total quality management dimensions with an observation of the results that are reached depending on the completeness, or limitations of these studies and the entrance and methodology in processing and analysis of the material.

Those processors that tried hard to address the issue of confusion between the qualitative dimensions of quality management and ethics that must be consistent with the policy of the Organization and senior management to participate effectively in the formulation of quality not only to ratify it.

As its customary in the morals of operation management that focus on qualitative dimensions important for the differentiation of product or service if the company wants to improve their competitiveness,

And provides for studies that focus on this aspect can not pay off only if relevant to business ethics, and this was confirmed to us in the concerns and the commandments of the American Society for quality control provided by the U.S. company, demanding it in the application confirmed that the mission of quality and a problem that administrative ethics and strategy at 
the heart of the concerns of senior management and have precedence in the strategic objectives of operations management in general and quality management in particular(Steeples,1994.pp73-75).

This means that the philosophy of these approaches ethics is an approach to understand the structure of a number of ethical principles with a specific objective, taking into consideration the relative importance of each dimension of the qualitative dimensions of the entrance to the Total Quality Management in this direction, and this explains the presence of a reciprocal and a link between these principles and variables and qualitative dimensions.

So we find in the formulation and determine the scope and ethical nature and principles the essential content of the "Total Quality Management" activity and this is what we found, consistent with the view of the both (Frigenbaum) inviting him to control the overall quality and (Crosby), who calls his philosophy to the "absence of errors" (Zero Defect) and continue with (Deming), who went far beyond to the stage of the principles applied and how that can be transmitted to the practice in the business field.

We can notice from the above that the overlap is clear between the philosophies to put the researcher farther to proceed in laying the theoretical frameworks that focus field process, we found the appropriate presentation of the framework theory to achieve what we went for a focused discussion of the views of progress in addressing the issue of ethical principles of objective quality.

And it will be offered towards the theoretical insight and rectify the contents of perceptions and views of both (Deming) and (Crosby) :

\subsection{Philosophy of (Deming):}

Philosophy of (Deming) concentrates on management practices with respect to quality and ethics and the competitive position, without focusing on the quality itself, and it philosophy seems clear by explaining the reasons for low quality and style of response.

Based on the foregoing, the researcher will address (Deming) approach in a summary as follows(Deming,1982,p.8).(a)Achieving a very constant quality improvement in order to remain within the circle of competition and continue to work there must be a goal or objective to improve the performance and competitiveness based on the qualitative dimensions and principles of business ethics and require the following: (i) Knowledge of current and anticipated problems in the future. (ii) Develop assignments to long-term planning. ( iii) Allocation of resources for research and education and maintain equipment and tools.(b) Understanding the new reality to the requirements of production systems and modern services and the idea of integration between these systems and information technology, this does not accept the normal levels of errors and the presence of Rejects.(c) Being away from the widespread inspection by the alternative of statistical evidence, as well as commitment to ethical principles that are based mainly in the quality product designed to serve the customer and their desire to achieve.(d)stop the act of baying items of lower cost , and the adoption of quality standards and the creation of delivery systems and build good relations with suppliers.(e) Find in depth the causes of problems: the duty of senior 
management is to work consistently in all areas and the relevant sections of quality, for the purpose of identifying the problems in order to determine the qualitative dimension which provides the management tool in solving problems or limitation in order to achieve relevance with ethics to be followed in the Organization which satisfy the customer and before that market.(f) Initiative the ways of modern training at work and provide the staff trends and ethical approaches that require compliance in quality work through the training.(g) Find modern methods of supervision and responsibility of supervisors to make the first development and update of quality, leads to the achievement of specific objective.(h) Remove fear and create an atmosphere of frankness and discuss the obstacles and quality of work between senior management and employees.(i) Remove the barriers between departments and sections of the company and make the workers in the research activities and services and production team one understand the "good governance" and "The idea is applicable", "protection and safety," the risk of the product.(j) Remove barriers that stand between the workers and their right to pride and boasting what they produce and their plans and goals by side senior management.(k)Adopt an approach to "quality awareness" training and rates of digital exclusion and the search for development aspects of other goals.(l) The expression of the above Axis practical mechanism led by senior management.

\subsection{Philosophy of (Crosby)}

The philosophy Crosby is based on a concept calls for "learning proficiency" rather than learning how to contain the amount of the error, and this comes in line with what went by the entrance of ethics (Kant's), which starts his theory on the basis of "Careful" and "the right idea due reflection "which requires workers to struggle to make their output conform to the specifications. Crosby said that the responsibility of poor quality in most American companies is due to managers because they do not want quality and they also want their other functions.

It seems that the lack of ethical orientation is due to the following reasons(Detoro,2003).

(i)Exercise the process of developing a centralized form of quality decisions, without taking into account the participation of others, because the process of improving quality is a cooperative nature, and it comes on top of ethical principles.(ii)The managers feels that the issue of quality can be to entrust to others, if this is proven true as an entry within the entry of moral rights, senior management should participate in decisions and a sense of quality workers in individual freedom, quality work is everyone's responsibility.

In light of the above in order to ensure "Total Quality Management" to achieve its freedom from errors "due to the high quality of its product, it seems useful to be taken into account the ideas that came out (Crosby), which is summarized as follows:(a) To emphasize the role of senior management in order to ensure that the program of "freedom from mistakes" is the correct approach, and thus reduces the cost and quality is an important basic task.(b) To encourage the style work teams that contribute to the achievement of the principle of "do it from the first times" and enhance this approach direction entrance moral individual who brought him (Nozick) and the entrance to his philosophy of virtue "meditation broad" or "excellent idea meditate before practice. (c) Building standards for quality in all sections of 
the company including the company's commitment to target the required specifications, and this is consistent with the direction of the entrance in utilitarian ethics, which emphasizes senior management to determine the ethical standards that guide managers in all levels.(d) Work to find new ways to supervise the workers and make their responsibility to achieve the required quality.(e) Awareness and attention toward quality episodes, a group of workers involved in the process of study collaborative ongoing aims to detect problems that obstruct the march of the work quality and work to provide appropriate solutions as well as their participation in the development of plans and objectives, and is this trend represent the other evidence from an ethical view which emphasized the theory of distributive justice that (Rawlsiam) came up with.(f) Initiative to develop new methods for training and education for all employees.(g) Adoption of the committee system and promoting awareness and qualitative assessment for its positive ramifications for workers(h) Development goals: is claimed by both a supervisor or the President, working in the oath or popularity to set a goal and seek to achieve through a specific time period, provided that this will help the target to achieve a remarkable development in the area of quality and production, and in this particular emphasized of ethics principle in transition this option.(i) senior management and employees should claim to research the problems, constraints and effects of relevant quality environmental, and identify and find solutions and proposals to them, and this idea represents entrance of moral transition to search for possible effects of the acts and actions internally and externally and delivered to all employees.(j) Remove barriers that stand between the workers, and work on discrimination of workers among themselves according to their interests and levels of performance in this direction.(k) Board of Quality: This included a group of advisers and experienced in the field of quality, meets periodically to discuss ideas and existing developments in the field of quality.(l) Work on the sustainability of this approach to become the sanction of the general attitude of the organization and its way towards progress, if it was not specific performance of the company or organization it will not improve its production and the company will lose the competitiveness, and this was confirmed by "Barnad" When he supported the concept of the moral entry " meaning as " that Objective of the Organization must be ethical and should be the target embedded in the fabric means that you should not provide the means to make ethical and objectives by focusing on quality, not profit.

The researcher found in his presentation of these two philosophies appropriate framework for an intervening all the concepts entrances ethical aforementioned "utilitarian, rights, justice, freedom, virtue," to reflect the on perceptions of the field of strategic ethical development to fit dimensions of Total quality management, without justifying this only under the pretext of the scarcity of models or philosophies, but we saw what we offered of the entrances and philosophies related to the link of quality which administered by the comprehensive development of the basic principles and strategies to business ethics and quality target, which represented a central aspect of our model is the default mode to move toward the side of the field.

Thus, we found appropriate to present basic principles, characteristics and traits in order to achieve this overlap and the link between the Axis of moral and qualitative. This has been 
reviewed in detail in tables(2-7) to serve the objectives of the analysis and interpretation, as follows:

Table 2. The first principle is "Do not harm"

\begin{tabular}{|l|l|l|l|}
\hline Moral & The character according & $\begin{array}{c}\text { Sequence } \\
\text { ac according } \\
\text { to Deming }\end{array}$ & $\begin{array}{l}\text { Sequence } \\
\text { according } \\
\text { Crosby }\end{array}$ \\
\hline No moral approach & $\begin{array}{l}\text { Selective approach focuses on the principle } \\
\text { of the relationship between senior leadership } \\
\text { and staff in developing policies and plans in } \\
\text { accordance with the environmental changes } \\
\text { of quality in the area requires it to provide the } \\
\text { personnel trends and ethical approaches } \\
\text { through training and learning for the purpose } \\
\text { of avoiding any potential harm. And support } \\
\text { the entrance to justice, and commitment to } \\
\text { address the trend of rights and duties and } \\
\text { powers applicable to the concept of the idea } \\
\text { expressed by the entrance of virtue by doing } \\
\text { good. }\end{array}$ & E, F, H, J & AA, C, L \\
\hline
\end{tabular}

Table 3.The second principle: "fairness and justice"

\begin{tabular}{|c|l|l|l|l|}
\hline Moral & The character according & $\begin{array}{l}\text { Sequence } \\
\text { according to } \\
\text { Deming }\end{array}$ & $\begin{array}{l}\text { Sequence } \\
\text { according } \\
\text { Crosby }\end{array}$ \\
\hline Fairness and & & $\begin{array}{l}\text { The entry of rights focuses on engaging processors and } \\
\text { salesmen and all those working relationship with the } \\
\text { decisions of the quality. While across the entrance of } \\
\text { justice provides the resources and necessary facilities } \\
\text { for work and the participation of all employees in } \\
\text { planning and goal-setting and within the entrance of } \\
\text { virtue, he stressed the need to apply the principle of } \\
\text { fairness in the work. }\end{array}$ & F, H & A, J \\
\hline
\end{tabular}


Table(4)The third principle of "transparency"

\begin{tabular}{|l|l|l|l|l|}
\hline Moral & \multicolumn{2}{|c|}{$\begin{array}{l}\text { The character according } \\
\text { To moral approach }\end{array}$} & $\begin{array}{l}\text { Sequence } \\
\text { according to } \\
\text { Deming }\end{array}$ & $\begin{array}{l}\text { Sequence } \\
\text { according to } \\
\text { Crosby }\end{array}$ \\
\hline Transparency & $\begin{array}{l}\text { Stresses on utilitarian entry in the application of the feedback } \\
\text { principle, while focusing entrance rights to the credibility and } \\
\text { respect for the opinions of the requests from the public, either } \\
\text { the entrance of justice stresses the encouragement to go to the } \\
\text { teams and the principle of cooperation and discrimination } \\
\text { working as a right and pride, and put the entrance to the } \\
\text { individual concept in this direction, and this is what we found } \\
\text { Appropriate when the recommended entrance virtue to tell the } \\
\text { staff with all information that can teach them how to think. }\end{array}$ & B, E, F, M \\
\hline
\end{tabular}

Table 5.The fourth principle: "voice"

\begin{tabular}{|l|l|l|l|l|}
\hline Moral & The character according & $\begin{array}{l}\text { Sequence } \\
\text { according } \\
\text { to Deming }\end{array}$ & $\begin{array}{l}\text { Sequence } \\
\text { according to } \\
\text { Crosby }\end{array}$ \\
\hline Voice & $\begin{array}{l}\text { Perhaps the most affirmed approach is selective } \\
\text { utilitarian entry purpose or goal and here lies this } \\
\text { philosophy towards building a curriculum that calls } \\
\text { for a qualitative approach is the work of organization } \\
\text { and others to respect this objective. And harmony with } \\
\text { the entrance of human rights in one of the issues } \\
\text { raised by hearing the views of others and to discuss } \\
\text { quality more than the obvious. The entry of justice } \\
\text { demands others to express their ideas and hear their } \\
\text { voice and whats appropriate. }\end{array}$ & L, H, M \\
\hline
\end{tabular}


Table 6. Fifth Principle: "integrity"

\begin{tabular}{|l|l|l|l|l|}
\hline Moral & & $\begin{array}{l}\text { The character according } \\
\text { To moral approach }\end{array}$ & $\begin{array}{l}\text { Sequence } \\
\text { according } \\
\text { to Deming }\end{array}$ & $\begin{array}{l}\text { Sequence } \\
\text { according to } \\
\text { Crosby }\end{array}$ \\
\hline Integrity & $\begin{array}{l}\text { The selective entry calls for raising the } \\
\text { importance of the quality objective, as it focused } \\
\text { on the development of mutual trust with all parties } \\
\text { and understanding between departments in order } \\
\text { to resolve all the problems. Showing the same } \\
\text { trend entry justice principle of good service, and } \\
\text { confirm the entrance of individual choice on } \\
\text { individuals convert to a form in the conduct and } \\
\text { behavior to determine what is true of each error, } \\
\text { and taught us the entry of virtue of good moral } \\
\text { and obligation of conduct takes us away from all } \\
\text { the methods of cheating and fraud. }\end{array}$ & J, M M \\
\hline
\end{tabular}

Table 7.Principle VI: "attention and care"

\begin{tabular}{|l|l|l|l|}
\hline Moral & The character according & $\begin{array}{l}\text { Sequence } \\
\text { according to } \\
\text { Deming }\end{array}$ & $\begin{array}{l}\text { Sequence } \\
\text { according } \\
\text { to Crosby }\end{array}$ \\
\hline Attention & $\begin{array}{l}\text { The selective entry cites the quality objective importance with } \\
\text { the accepting of the fact that any increase in cost is } \\
\text { unacceptable/while the entry of human rights present giving } \\
\text { workers the right attention and care both by locating the } \\
\text { necessary powers. Justice entry trends that there is no difference } \\
\text { between individuals and the responsibility of quality work is the } \\
\text { and }\end{array}$ & $\begin{array}{l}\text { responsibility of everyone. Thus comes the entrance of virtue to } \\
\text { confirm the account that your plans take into consideration by } \\
\text { the owners }\end{array}$ & A, G D, F, J \\
\hline
\end{tabular}

\section{The Fit Between The "Strategies of Business Ethics" and "Approach to Total Quality Management ":}

After characterizing and identifying the strategic principles of "Ethical Business" and dimensional quality "to the approach of the Total Quality Management," according to what was previously displayed in the past researches and responded to complete the theoretical side to our subject, we offer the concept which we named by the "title" which will highlight 
the contents "The Fit" between the two Axis previously mentioned that the current study - in the research problem - targeted mainly searching for a model integrated as much as possible to achieve the fit case among the pivotal study and to answer its questions.

(William) points that the subject of the fit was applauded by researchers even though its still in its infancy, especially in the field of strategic management or research in the field of business ethics, in this lies the importance of appropriate in this field to the following (Tom,1985; William,2005).(a)Shed - Study of the fit - light on the possibility to identify the components of strategy, being studied, and ranges of application.(b) Set - study of - the fit the dimensions and factors or principles became an impact on the achievement of compatibility between some strategic decisions regarding the diversification of its products and the conditions of the surrounding environment.(c) The failure reasons of some business organizations, primarily in the inability to achieve compatibility between some of the factors relevant to the fit administrative problem required to study.

Thus, what we presented, our appreciation is mainly led to theory Interests widening in addressing the objective of convenience to come study of (Camillus) a significant milestone in this direction by providing a presentation the fit schools, as follows(Camillus,1984; Kate,2007).

\section{1. "Strategy Formulation School"}

\section{2. "Strategy Implementation School"}

\section{3. "Integrated, Formulation Implementation"}

\section{4. "Network School"}

\section{5. "Strategic Choice School"}

\section{6. "Gestalt School"}

We have found in the focus on the "Strategy Implementation School" and" Gestalt School" the importance that fit with our approach concepts to "The Fit "in this study to be a way to improve competitiveness. Including of the posed variables accounted for practically the pillars of the items of interest in our study the fit and may view the concerns of researchers in the framework of these two schools confirms what we have studied earlier.

(Daniel) recalls in his study of the importance of the fit factors between countertrade and strategic activity.

(Charies) attributed the successful competition for some U.S. companies to achieve the fit between the culture of the organization and strategies(Carrels.1999).

(George) found that the best performance is achieved through the fit technology on the one hand and the activities of the organization, strategy framework, and leadership on the other hand(George,2001).

The study (Skinner) to a group of American companies in order to achieve the fit strategies and decisions between the quality and management enhances the company's success and 
gives it a competitive advantage.

Studying (Kopelman) theories recalls that we should work to the fit between the dimensions of quality object and quality management and decisions if we want to comply the needs and desires of the consumer(Kopelwan,1990).

(Toyner) raises the concept of the fit in reconciling the elements of the organization and its strategies(Toyner,1997).

From the foregoing we can conclude that what has been written about the Relationship between "Strategies of Ethical "and "Total Quality Management ", is still in the process concerns the theory - and this is what we stated earlier - and which could be adopted is an approach to the establishment of empirical studies dealing with models hypothesis in discussing the subject of the fit.

At this point our study come to a very critical point which is to measure the "The fit between strategies immoral business and the approach to" total quality management "and its impact in improving performance and competitiveness.

Perhaps in that we have put forward in parallel with contemporary research in the area of interest in our study.

It should be noted here that the attention of researcher theoretical concept to The fit targeted new approach crystallization in how they can improve performance and competitiveness of the way between the strategies appropriate ethical and quality management approach.

This approach focuses on the basic idea that improved performance and competitiveness of firms is determined in the light of the exploitation of the strengths of aspects of the internal environment, and perhaps we can use aspects of the external environment, but we confine ourselves to aspects of the internal environment to reflect the changes for improving performance and competitiveness, responding to do fit process and reflected by our model.

(Boseman) sets those aspects of the superiority of the company's competitor in variables, type of service, innovation, distribution and delivery.

(Bamberger) sets that the role of the ability to support and promote competitive advantage and put the resources and skills that are characterized by the company, which means all the conditions and possibilities that are characterized by the company (Bamberger,1989).

For (Cleuck) he accompanied it with activities; marketing, distribution, production, personnel, finance, research and development, organizational structure (Glueck,1988).

In this context, (wheelen and Hunger) proposed three variables essential in the analyzing and diagnosing the strengths of the business which is the organizational structure, culture and resources.

On these basis researchers, found in (Bamberger) and (Cleuk) contribution to the unification of efforts in the company in a framework that includes all activities which, in addition to its application that works in different businesses, keeping the objective and subjective 
parameters.

\section{A Model Study}

The study of basic research variables elaborated in Figure (3), which represented the basic principles of business ethics and qualitative dimensions to the approach of Total Quality Management, as clarified by researchers earlier, required the establishment of a model reflecting the potential for the fit them with the measurement of the impact of these the fit to improve performance and competitiveness, and our direction in the formulation of the model is based on the following assumptions:

6.1. The possibility to measure each of the strategic principles of business ethics and ever dimension of quality to the approach of Total Quality Management and community sponsors or solo, is such aspect available in theory it gained the importance in the treatment of applied field where there are requirements of the study and areas of application.

6.2. The consistent of variables with environment characteristics, the researchers require the preference of some study parts to be applied in industrial organizations.

6.3. Comprehensive model and the possibility of testing.

The current study adopted by the researcher in the diagnosing his problem led to one diagnosis which was determined through deduction and induction trends of senior management on the basic principles "for Business Ethics" and qualitative dimensions to the approach of "Total Quality Management ", and the extent of support and assigned to a test of the fit between them and the impact on competitiveness, the conclusion above can be strengthen by proving the credibility of the model of this study before major change which will be an important pillar in the treatments applied, so have contributed to this study and the model in providing a conceptual framework for the decision maker with regard to identifying the most important decisions in building the efficient management operation. And it will be able to answers the questions raised and raised in the problem of the study. 


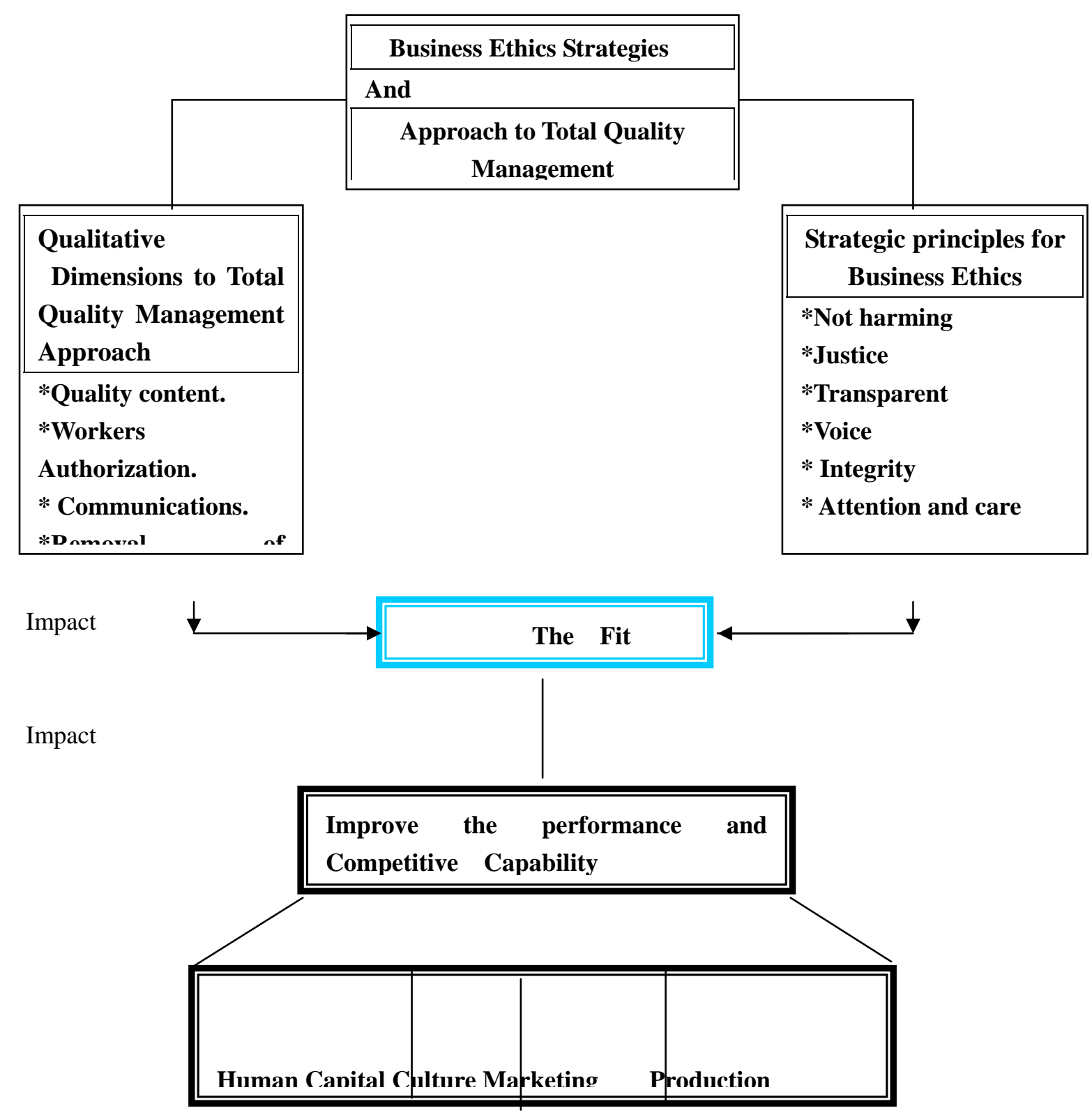

Figure 3. Model study

\section{Conclusions and Recommendations}

This study represents an effort modest by the researcher to answer the questions the problem of the related study towards the characterization of a central core principles "ethical business" and qualitative dimensions "to the approach of the department overall quality" which have been submitted in accordance with the methodology of studies of fundamentalism, was intended to researcher, first, expand the theoretical knowledge existing in the field of "business ethics" and "quality management college" in the potential attempts to apply the field, and second, to provide scientific information that benefit management companies in 
taking the necessary decisions on the "The Fit" between the principles of ethical business and qualitative dimensions and the reflection in improving the performance and competitiveness.

Through the extraction and stability we have diagnosed and determine the reality of the Axis variables of the study above, in addition to the diagnosis and identification of indicators to improve performance and competitiveness.

Based on the diagnosis, the current paragraph is the epitome of the efforts of the researcher, including the findings of the study results and conclusions of the theoretical basis for it; it is also at the same time representing the base for the development and formulation of recommendations.

\subsection{Conclusions: These include a summary of the theory of concentrated as follows:}

7.1.1. That the study methodology in light of contemporary concerns centered in two-way, first, deals with what lies beneath the concept of "dimensional quality to the approach of total quality management, the philosophy and application, and based on this concept in the framework of concepts and modern models to the concept of "The Fit" in theory between the Axis and their impact on improving the performance line and improve competitiveness.

7.1.2. There is a need to link the central business ethics and the approach to Quality management, or to say that there is a missing link between the two Axis, can be achieved through the Integral framework towards achieving the "The Fit" between the two Axis, which is an important pillar in the work, objectives and plans required to improve the performance and competitiveness.

7.1.3. The study indicates the need to focus on the requirements for consumers as a rule can build upon them in defining the principles in the "business ethics" to be the fit by improving the competitiveness of the target, and such perception is in line to the wide limits with the view of the majority of global organizations.

7.1.4. The process of identifying qualitative dimensions to the entry of "total quality management" of the most prominent responsibilities of senior management, which should derive from the nature of the events and activities and objectives of the strategic planning process for the company thus its decisions.

7.1.5. This means that the philosophy of this administration is the gateway to understanding the structure of these dimensions, and this explains the presence of an interactive process led by "The Fit `between these dimensions and ethical principles.

7.1.6. In order to facilitate the task of implementing the foregoing, the study indicated the need to focus on the philosophies of "Crosby" and "Deming" in a suitable way to reflect the perceptions of a leader in the field of ethics of work without justification for this limit ourselves under the pretext of the scarcity of models or philosophies, but to tell us point of what our offer has comprehensive and rear positions to achieve the fit requirements.

7.1.7. The study confirmed that the approach which was adopted by the researcher in the diagnosis of his problem led in the light of many of Administrative Studies, who paid 
attention to its subject in a precise diagnosis of the trends of the organizations and senior management on ethical principles the fit to the dimensions of quality to the entrance of quality management with the strongest effect in improving performance and competitiveness, which have been developed a group for the purpose of the questions to be answered, the results reported that these questions are designed objectively and accurately, as most of the analysis found the answers to these questions.

7.1.8. The conclusion above can be supported, through the credibility of the model study, as achieving and addressing the problem and objective of the study to identify how to follow up on each Axis on the performance and competitiveness, also to give an assessment and weight to the issue of "The Fit" with each other, so contributed to this study provide a conceptual framework for the decision maker.

7.1.9. The study confirmed the reliability of the variables "do not do harm, fairness and justice, transparency, sound, integrity, attention and care" to represent the basic principles of business ethics. Diagnosed as study variables "quality content, enabling employees, communication, remove barriers" to represent the qualitative dimensions of total quality management.

\subsection{Recommendations:}

Supplemented to the imperatives of the study, we will discuss in this paragraph, a set of recommendations and proposals that can help departments researched companies in improving performance and competitiveness through the achievement of the fit between the principles of business ethics and qualitative dimensions of the Total qualitative dimensions, and that relying on the results and conclusions of study raised previously as follows:

7.2.1. Importance of adopting a model illustrated by the study in the light of the different quality assessment activities in accordance with ethical principles and dimensions of quality and the fit between its tow axis, improving performance and competitiveness can not be done in isolation from the relationship between those variables.

7.2.2. The study includes a specimen requires the attention of some companies if they want to improve their performance, and here we must focus attention and be aware of the importance of "The Fit" between these Axis.

Among the recommendation is to achieve "appropriate" as follows:

7.2.1.1. strengthen the relationship between co-workers, since workers would receive moral support from their colleagues at work when developing new innovative ideas to improve the quality of the product or service.

7.2.1.2.establish an independent unit to obtain information from the environment and analyze them.

7.2.1.3. give an extensive power to quality managers in the amendments to the plans and participate.

7.2.1.3. confirm the principle of cooperation and consultation between administrations and 
departments with regard to performance.

7.2.3. The researcher recommends the need to detect and diagnose accurately, and other variables studied addition to these variables and elements and determine their impact in improving performance and competitiveness.

7.2.4. The study proposes the, "the fundamental principles of business ethics of the "Total Quality Management" based on proposals theoretical frameworks to the entrance of selective business ethics and the human rights entry and the theory of distributive justice and the single entry and then the virtue entry and ethics, and insight into the contents of the philosophy of "Deming" and "Crodby" to address one of the Axis the "The Fit" to the approach of total quality management, and corporate business to have an objective point of view to accommodate these principles, which affect the possibility of improving the performance and competitiveness.

7.2.5. An attempt to harness the indicators to improve "the performance and competitiveness" (production, marketing, culture, human resources) and for the benefit of the development organizations in the competitive position that is consistent with perceptions of future.

7.2.6. Within the framework of future studies, this study suggests the need for studies that represent an initial attempt to the areas of new knowledge within the fields of operations management of strategic management in particular, with regard to the concepts of principles of business ethics and qualitative dimensions of the task to the entrance of quality management and appropriate them and indicators a better performance and competitiveness, and this is a necessity to repeat this study and its dimensions or add other variables in the industrial or service sectors may be preferable to use the model adopted in the study, in order to work on solving the problems of these sectors in improving the quality of the products or services and to achieve competitive commodity or service.

\section{References}

American Society For Quality Control (ASQC), Standard Q1-1986, Generic Guidelines for Auditing Quality System., p.8.

Bamberger, in golf. (1989). Developing Competitive Advantage In Small And Medium Size Firms,(Long-Range Planning), Vol.22.No.5. p.82.

Chen, A.Y.S. \& Williams, P. F. (1997). Reinforcing Ethical Decision Making through Corporate Culture, Journal of Business, Pp.855-865, 3.Kant, I. Critique of Practical Reason, translated by Mary Gregory (N.Y: Cambridge University Press), pp83-86

Crosby, Philip, B. (1989). Quality Is Free, N.Y.MGgraw Hill Book, Company Inc. P.28.

Childress, J. F. (2005). Principles of Biomedical Ethics, N.Y. Oxford University Press, p.63.

Camillus, N. Venkatraman, John c. (2009). Exploring The Concept of Fit In Strategic Management, Academy of Management, No.3. pp.513-520.

Carrels, D, Zimmerman. (1999). Quality: Key to Service Aging, The New York Time, (April.4), 
p.53.

Deming, Edwards, W. (1982). Quality, Productivity, And Competitive Position, (United States of America, Inc,).p.8.

Don, Hoernschemeyer. (Des,1988). Creating Conditions for Excellence, Manufacturing System p.93.

Detoro, Jeff., .Feb 2003). American Leaders Competing For Quality, (Manage),Vol.40.N4p.16.

Glenn, E, Hayes.,(2010). Quality And Production, The New Challenge, (Wheaton, 111. Hitchcock Publishing Company).,.p.46.

Grant, I, f. (1997) Ethics: Amoral Is Not Good Enough, Management, 44(2). p.50.

George, Lab Ovitz. (April 2001). Questions of Quality, Quality Today p. 26.

Glueck, W. F. and Jack, Lawrence. (2007). Business Policy and Strategic Management, (3 ${ }^{\text {rd }}$. ed McGraw- Hill Book Co., Inc.. p. 156.

Hodgeits, Richard. (July-August 1994). Quality Lessons from Americas Badrige Winners, Business Horizons, p.74.

Harrison, M. Trice and Janice M .Beyer. (2009).Using Six Organization Rites to Chang Culture/ In Gaining Control of The Corporate Culture, San Francisco, Josses-Bass, 371.

Ishikawa, Kaoru. (1985). What Is Total Quality Control, The Japanese Way, Englewood Cliffs, Nj: Prentice,Inc, p.31.

Juran, J, M. (1988). Quality Control, Handbook, $4^{\text {th }}$,ed.N.Y. McGraw-Hill Book Company Inc. p.25.

Kant, I.(1997) Critique of Practical Reason, translated by Mary Gregory, N.Y: Cambridge University Press),

Kate, Bertrand. (Aug 2007 ). New Product Success Starts with Homework, Business Marking, p.18.

Kopelman, Richard, E. (1990). The Role of Climate and Culture in Quality, By Schneider Josses Bass, Inc, Publishers, 1990. p.282-318.

Lee, Tom, Perry. (1993). Real-Time Strategy, N. Y. John Wiles and Sons, Inc. p.11.

Linkow, Peter. (Nov. 1989). Is Your Culture Ready for Total Quality, Quality Progress, p.69.

Miller, Charles. (2007). The Quality Audit /A Management Evaluation Tool, N.Y. McGraw-Hill Publishing Company, P.130.

Milakovich, M., Spring. (1991). Total Quality Management in The Spring, National Productivity Review, p.198.

Murphy. E. (1999). Character and Virtue Ethic in International Marketing an Agenda For 
Mangers, Researcher and Educators. Journal of Business Ethics, pp.107-124. http://dx.doi.org/10.1023/A:1006072413165

Mayo, Johns, AT and T. (April 1991). Management Question for Leadership in Quality, Quality Today, pp.34-35.

Machold and P. K. Ahmed. (June 2004 ). The Quality and Ethics Connection. Total Quality Management Vol.15.No.4 pp.533-537.

Rosa bet, Moss, Canter. (July-Aug 1989). Power Failure in Management Circuits, Harvard Business Review, p.43.

Roth, B. (1993). Is It Quality Improves Ethics or Ethics Improve Quality ? The Journal of Quality and Participation, 16(5). pp.6-11.

Rawls, J. (1971). Theory of Justice, Harvard University Press, p. 243.

Steeples,M.M. (Jun 2006).The Quality-Ethics Connection, (Quality Progress), pp.73-75.

Schroeder, Roager, G. (1989). Operation Management Decision Making in The Operation Function, (3 ${ }^{\text {rd }}$. ed. MGgree-Hill International), p.593.

Tobin, Lawrence, M. (Nov,1990), The New Quality Landscape: Total Quality Management, System Management, Vol.41, No.11.pp.10-14.

Terrence, E. Deal and Allen A. Kennedy. (2008). Corporate Cultures: The Rites and Rituals of Corporate Life: Reading, M. A. Addision Westey, p.4.

Thomas, H. Davenport. (1994). Process Innovation. Cambridge Harved University Press. p.69.

Tom, Peters and Austin. (1985). Passion for Excellence, undom House,. p.11.

Toyner, David. Lessons in Fit. Management Decision, Vol.24. No.1. p.12.

Vijay, Sathe. (1985).Culture and Related Corporate Realities, Homewood: Richard D. Lrwin, Inc,.p.15.

Weihrich,Heinz. (July-August, 1994). Quality: The Imperative, The Jungle, And The Two-Factor Theory, Quality Management, p.17.

Water, C.D.J. (1991). Introduction to Operation Management, Wesley Polishing, Co, Britain, p.36.

William, Glaberson. (April 2005). Listening to The Consumer Again, Quality Today, p.63. 